\title{
Seasonal migration of sika deer in the Oku-Chichibu Mountains, central Japan
}

\author{
Akiko Takii ${ }^{1, *}$, Shigeyuki Izumiyama ${ }^{2}$, Takashi Mochizuki ${ }^{3}$, Tadanobu Okumura ${ }^{4}$ and \\ Shigeru Sato ${ }^{5}$ \\ ${ }^{1}$ Interdisciplinary Graduate School of Science and Technology, Shinshu University, 8304 Minami-Minowa, Kami-Ina, \\ Nagano 399-4598, Japan \\ ${ }^{2}$ Faculty of Agriculture, Shinshu University, Nagano 399-4598, Japan \\ ${ }^{3}$ Akatsuki Wildlife Research Office, Shizuoka 422-8046, Japan \\ ${ }^{4}$ Wildlife Management Office, Inc., Tokyo 194-0215, Japan \\ ${ }^{5}$ Forestry Department, Nagano Prefecture, Nagano 380-8570, Japan
}

\begin{abstract}
Movements and seasonal home ranges of 6 GPS collared sika deer were investigated at the Oku-Chichibu Mountains, central Honshu, from April 2009 to March 2010. All deer migrated between discrete summer and winter home ranges. The linear migration distance ranged from 2.5 to $31.9 \mathrm{~km}$. Mean elevation during the summer and the winter ranged from 980 to 1,782 $\mathrm{m}$, and from 1,204 to $1,723 \mathrm{~m}$, respectively. Two deer were upward migrants and 4 deer were downward migrants. Taking into consideration of the relatively small snow accumulation in the summer home range, the possibility of autumn migration to avoid deep snow is low. The percentage of steep slope in the winter home range was higher than that in the summer. Bamboo grass was not found in the summer home range, but was predominant in the winter home range. Road density decreased in the winter home range compared to the summer. Only 2 out of 6 deer stayed mainly in the wildlife protection area during the winter. Our results indicate that the autumn migration was affected by winter forage and human disturbance, thereby assured the survival of the deer during winter.
\end{abstract}

Key words: central Japan, Cervus nippon, GPS telemetry, seasonal migration, wildlife protection area.

Migration, a movement between discrete winter and summer ranges, is one of the common movements of ungulates in middle to high-latitude regions (e.g., Craighead et al. 1972; Tierson et al. 1985; Garrott et al. 1987; Kufeld et al. 1989; Boyce 1991; Nicholson et al. 1997; Ramanzin et al. 2007; Zweifel-Schielly et al. 2009). Many studies have indicated that temperate cervids exhibit seasonal migration due to the presence of snow which limit locomotion and food availability (e.g., Fryxell and Sinclair 1988; Nelson 1995; D'Eon and Serrouya 2005). Meanwhile, migratory movements may be adopted to access high quality food and/or to reduce the risk of predation (Fryxell and Sinclair 1988). In Japan, natural predator of sika deer (Cervus nippon centralis), wolves (Canis lupus), no longer exist since 1905, and man became the only creature to control deer population. Among human activities, hunting activities are known to affect the behavior of deer (e.g., Kufeld et al. 1988; Vercauteren and Hygnstrom 1998; Sunde et al. 2009), but little is known about the effect of hunting on deer migration (Kamei et al. 2010).

Sika deer is the only cervid species widely distributed in various habitats from subtropical to boreal zones of the Japanese Islands (Takatsuki 2009). Movements of sika deer have been described for several areas in Japan. In deciduous broad-leaved forests and evergreen coniferous forests of northern Japan, sika deer populations are known to exhibit migratory (Honma 1995; Izumiyama and Mochizuki 2008), sedentary (Nagata 2005), and both migratory and sedentary movements (Maruyama 1981; Takatsuki et al. 2000; Uno and Kaji 2000; Igota et al. 2004), whereas in evergreen broad-leaved forests of southern Japan, only sedentary movements are known (Shigematsu et al. 1995).

*To whom correspondence should be addressed.E-mail: 10st413j@shinshu-u.ac.jp 
Migratory female sika deer in eastern Hokkaido, the northernmost island of Japan, are known to exhibit altitudinal and long-distance migration (i.e. $>10 \mathrm{~km}$ ) (Uno and Kaji 2000; Sakuragi et al. 2003; Igota et al. 2004). Snow and bamboo grass cover were the major factors affecting seasonal migration (Igota et al. 2004). However, little is known about the seasonal migration of deer in Honshu. Two studies have indicated altitudinal migration (i.e. movements between higher elevation summer range and lower elevation winter range) in Omote-Nikko, central Honshu and Mt. Goyo, northern Honshu suggesting that snow is the main cause of migration (Maruyama 1981; Takatsuki et al. 2000).

Sika deer in the western Oku-Chichibu Mountains, central Honshu, have never been studied. In addition, contrary to previous studies, we analyzed the movements of deer in less snow accumulation area. Thus, if the deer exhibit migratory movements, migration should be stimulated by factors other than snow. Moreover, it is notable that a large area of western to eastern Oku-Chichibu Mountains is designated as wildlife protection area (WPA), where hunting is forbidden generally with an exception of control kill in specific areas. WPA is known to function as a refuge for sika deer during the hunting season in Tanzawa Mountains, south-central Honshu (Kanagawa Prefecture 2007), thereby the movements of deer in our study area may also be relevant to WPA.

The objective of this study was to identify seasonal movements and home ranges of sika deer in the western Oku-Chichibu Mountains. We hypothesized the deer movements would be more sensitive to human disturbance such as hunting activities and/or winter forage abundance in the study area. In order to obtain detailed information on the movements of each deer as well as due to the difficulty of radio-telemetry in the steep topography, we employed GPS telemetry. We will illustrate the detail of the movements and the seasonal home ranges using topographical features, critical winter forage (i.e. bamboo grass), road density and utilization of the WPA, to better understanding their movements in the mountainous region of Honshu.

\section{Materials and methods}

\section{Study area}

The study area $\left(1,584 \mathrm{~km}^{2}\right)$ is located in and around the Oku-Chichibu Mountains, which extends across Nagano, Yamanashi, Saitama and Gunma Prefecture, central Japan (Fig. 1). Two thirds of the study area is part of the Chichibu-Tama-Kai National Park, established in 1950. We captured the deer in Kawakami Village, located at the foothills of the western OkuChichibu Mountains. The topography of the mountainous area exhibits steep slope with deep valleys and rocky mountain ridges. Elevation ranges from 530 to 2,601 m and there are over 20 peaks with elevation higher than $2,000 \mathrm{~m}$.

At Nobeyama meteorological station $\left(35^{\circ} 57^{\prime} \mathrm{N}\right.$, $138^{\circ} 28^{\prime} \mathrm{E}$; $1,350 \mathrm{~m}$ a.s.1.), located $9 \mathrm{~km}$ west from the Kawakami Village Office, annual mean temperature was $7.2^{\circ} \mathrm{C}$ (minimum: $-25.0^{\circ} \mathrm{C}$; maximum: $31.0^{\circ} \mathrm{C}$ ) and annual mean precipitation including snow was $1,435 \mathrm{~mm}$ (range $=1,031-1,777 \mathrm{~mm}$ ) for 2000-2009 (Meteorological data of Nagano Prefecture, Nagano Local Meteorological Observatory, Nagano). According to the 30-year means for the period 1971-2000, maximum snow depth in the study area including the highest ridges ranged from 9 to $44 \mathrm{~cm}$ (Japan Meteorological Agency 2002).

The dominant vegetation in the study area differs with elevation (Nagano Prefecture 1976). In the alpine zone ( $\geq 2,500 \mathrm{~m}$ a.s.1.), alpine dwarf pine (Pinus pumila) is prevalent in small patches but due to small snow accumulation, snow-patch vegetation does not exist. In the upper subalpine zone (2,200-2,500 $\mathrm{m}$ a.s.l.), evergreen coniferous forest consisting mainly of Veitche's silver fir (Abies veitchii) and Marie's fir (A. mariesii) predominate. Lower-subalpine zone (1,700-2,200 m a.s.1.) mainly consists of Japanese hemlock (Tsuga diversifolia) forests and mixture of Erman's birch (Betula ermanii) forests. The understory of evergreen coniferous forest is alpine rose (Rhododendron metternichii seib et zuckmoss), azalea (Rhododendron spp.), moss or bamboo grass (Sasa spp.) (Nakata 1987).

The landscape of upper montane zone (1,000-1,700 m a.s.1.) of Kawakami Village differs significantly compared with the rest of the study area. Japanese larch (Larix kaempferi) plantations and cropland (e.g., lettuce) is widely distributed (Nagano Prefecture 1976) in Kawakami Village. However, deciduous broad-leaved forests predominate in other areas, with exception of the south of Mt. Kinpu where Japanese larch plantations is dominant (Ministry of the Environment 1997). The deciduous broad-leaved forest of upper montane zone consists mainly of beech (Fagus crenata), Japanese beech (F. japonica) and Japanese oak (Quercus crispula) (Ministry of the Environment 1979a, 1988). In the lower montane zone (below 1,000 $\mathrm{m}$ a.s.1.), there are patches of 
Japanese cedar (Cryptomeria japonica) and Japanese cypress (Chamaecyparis obutusa) plantations, deciduous broad-leaved forests consisting mainly of Konara oak (Q. serrata), sawtooth oak ( $Q$. acutissima), Japanese chestnut (Castanea crenata) and zelkova tree (Zelkova serrata) (Ministry of the Environment 1979a, b, 1988).

According to the block count method conducted in October 2004 and 2010, the estimated density of sika deer at two areas of Kawakami Village was 6.7-8.2 deer $/ \mathrm{km}^{2}$ and $4.5-15.3 \mathrm{deer} / \mathrm{km}^{2}$, respectively (Nagano Prefecture 2011). The number of deer harvested by control kill and game hunting is dramatically increasing in Kawakami Village from 2007 to 2009 (152 deer, 287 deer and 874 deer harvested in 2007, 2008 and 2009, respectively: Kawakami Village Office, unpublished data).

At the center of the study area, there is a large WPA $\left(344.7 \mathrm{~km}^{2}\right)$, surrounded by hunting zones (Fig. 1). The WPA were designated by the Prefectural Governments from 1950 to 1965 . In recent years, control kill is conducted in the main ridge of the eastern Oku-Chichibu Mountains during winter for several days, and total number of deer harvested was less than 10 in 2009. Deer hunting is permitted in the hunting zones from November 15 to February 15.

\section{Deer capture}

We captured 13 deer ( 7 females and 6 males) in Kawakami Village during April and May in 2009. The deer were immobilized with dart-gun, using a mixture of Ketamine-HCL (200 mg) and Xylazine-HCL (200 mg) as a tranquilizer. Deer age was estimated by tooth replacement and tooth wear. We weighed body mass of deer and attached a GPS collar (Tellus 5H1D, Followit AB, Lindesburg, Sweden) to each deer. The GPS collar was scheduled to acquire a GPS position every $30 \mathrm{~min}$ utes, and to emit VHF beacon every 8 hours per day with an estimated battery life of approximately 10 months. We downloaded the GPS data from the collar by using a RCD-04 Terminal (Followit AB, Sweden), external antenna and laptop PC. Data downloading was conducted every 1 or 2 months. We attempted to drop off the collar remotely as soon as the VHF beacon denoted low battery. After the collar retrieval, all GPS data were downloaded directly from the collar and imported into a GIS system (ESRI ArcGIS 9.3). Animal capture and handling followed the policies and guidelines provided by the Nagano Prefecture.

\section{Data analysis}

Six out of 13 GPS collars showed malfunction. One deer died after 2 months from capture. We used 6 deer ( 1 male and 5 females including 2 yearlings) with more than 200 days of tracking period to analyze the seasonal movements. Because of the high GPS fix acquisition and 3D fix rates, we did not screen the GPS data, but eliminated obvious anomalies representing impossible GPS data (D'Eon et al. 2002). Locations of individual deer were stratified into summer home range, autumn migration, winter home range and spring migration by visual inspection of mapped locations plotted sequentially by date (D'Eon and Serrouya 2005). Seasonal home range (i.e. summer and winter) was delineated by the positions of an individual deer, which stayed in a specific area for more than 30 days without moving no further than $2 \mathrm{~km}$ to any one direction within a day. We calculated the center of activity of the seasonal home range by averaging the longitude and latitude of the GPS fixes (Hayne 1949). Migration distances were calculated by straight-line distance (linear distance), and total distance of the connected lines of the consecutive GPS fixes (actual distance) between the center of activity. In case of deer with two different winter home ranges, we used the earlier winter home range to calculate its migration distance.

We calculated $95 \%$ and $50 \%$ fixed kernel seasonal home ranges (Worton 1989), using the adehabitat package for the $\mathrm{R}$ software (Calenge 2006) with reference smoothing 'ad hoc' (Pellerin et al. 2008). We report the $50 \%$ home range as an area of core utilization.

To evaluate the seasonal home range characteristics of each deer, elevation, slope, aspect, coniferous cover, bamboo grass availability, road density and the overlap ratio of the WPA were evaluated for each seasonal $50 \%$ home range (i.e. core area) using Arc View Spatial Analyst software (ESRI 1996). Elevations were determined using 10-meter digital elevation model (DEM) (Fundamental Geospatial Data: National Land Agency, Geospatial Information Authority of Japan, Tokyo). Slope and aspect were calculated from the 10-meter DEM using Arc GIS Spatial Analyst extension (ESRI 1996). We classified slope and aspect into two categories: slope $\geq 30^{\circ}$ and $<30^{\circ}$, and aspect from 90 to $270^{\circ}$ (southerly aspects) and the other (northerly aspect). Evergreen coniferous forests, Japanese cedar and Japanese cypress plantations were classified as coniferous cover using the vegetation map (Ministry of the Environment 1997). 
We investigated the bamboo grass MDR (multiplied dominance ratio) within the summer and winter core area of each GPS collared deer. MDR method was employed because of the simple procedures and it correlates closely with the dry weight of weeds (Kobayashi et al. 2003). We placed 25 quadrats $(2 \times 2 \mathrm{~m})$ at the intersection of 10 $\mathrm{m}$ grid square within the $50 \times 50 \mathrm{~m}$ plot, and measured the coverage (\%) and maximum height of the bamboo grass within each quadrat. MDR $\left(\mathrm{m}^{3} / \mathrm{m}^{2}\right)$ was calculated by multiplying the mean cover $\left(\mathrm{m}^{2} / \mathrm{m}^{2}\right)$ and mean height (m) of the bamboo grass within each study site. Field survey was conducted from June to July 2011. To assess the human disturbance of the seasonal home ranges, we calculated paved and dirt road densities $(\mathrm{m} / \mathrm{ha}$ ) for each seasonal $95 \%$ home range. Overlap ratio of the WPA was calculated for summer and winter core area. The roads excluding the section closed to traffic and borderline of the WPA were manually entered into the GIS software using the 1:25,000 topographic maps and WPA maps published by Prefectural Government in 2008, respectively. For deer with two winter home ranges, we used the home range with longer duration of stay to analyze the home range size and characteristics.

The summer and winter home range size of female deer were analyzed using Wilcoxon's signed rank test. Statistical analysis of the home range characteristics were conducted between the seasonal home ranges of individual deer. Mean seasonal elevation were evaluated using Mann-Whitney $U$ test. Other seasonal home range characteristics were evaluated by Chi-square test. All statistical analysis were conducted using the SPSS software package version 11.5. Data were presented as mean \pm standard deviation.

\section{Results}

\section{Seasonal movements}

Of the 6 GPS collared deer analyzed, GPS fix success rate was $92 \pm 6 \%$ (range $=81-96 \%$ ), and 3D fix percentage was $89 \pm 2 \%($ range $=86-91 \%)($ Table 1$)$. Tracking period ranged from 209 to 342 days. Due to the GPS collar malfunction, we were not able to track 2 GPS collars (nos. 12M and 13F) until their estimated GPS battery life.

All the GPS collared deer were migratory with distinct summer and winter home ranges (Fig. 1). During migration, deer migrated north, northeast and southeast to winter home range, crossing a high divide of Oku-Chichibu Mountains which is the Prefectural border. The summer home range of 5 deer was within Kawakami Village. Deer no. $1 \mathrm{~F}$, the only deer captured during the spring migration, summered in Yamanashi Prefecture, linear distance of $31.7 \mathrm{~km}$ southwest from the capture point. All the deer had winter home range outside Kawakami Village and stayed in adjacent Gunma, Saitama and Yamanashi Prefecture. Deer nos. 6F and 7F had two discrete winter home ranges. Deer nos. $6 \mathrm{~F}$ stayed at her first winter home range until December 23 (38 days), then moved $6.8 \mathrm{~km}$ westwards and stayed until late March ( $\geq 99$ days). Deer no. 7F stayed at her first winter home range until December 31 (58 days), then moved $1.2 \mathrm{~km}$ eastwards and stayed until March 20 (79 days).

All female deer departed their summer home range from October 8 to November $3(n=5)$ and settled down to their winter home range within 12 days (Table 1). The only male deer (no. 12M) we tracked departed from the summer home range about a month earlier than the female deer.

Table 1. Tracking period, GPS fix success rate, autumn migration period and migration distance of GPS collared deer captured in Kawakami Village, Nagano, 2009, with $>6$ months tracking

\begin{tabular}{llccccccc}
\hline \multirow{2}{*}{ Deer $^{\mathrm{a}}$} & Age & $\begin{array}{c}\text { Capture } \\
\text { Date }\end{array}$ & $\begin{array}{c}\text { Tracking Period } \\
\text { (days) }\end{array}$ & $\begin{array}{c}\text { Fix Success Rate } \\
(\%)\end{array}$ & $\begin{array}{c}\text { 3D Fix Rate } \\
(\%)^{\mathrm{b}}\end{array}$ & \multicolumn{2}{c}{$\begin{array}{c}\text { Autumn Migration } \\
\text { Period }\end{array}$} & \multicolumn{2}{c}{ Migration Distance (km) } \\
\hline no. 1F & Adult & Apr 15 & 337 & 96 & 91 & Oct 31-Nov 13 & 31.9 & 47.3 \\
no. 2F & Yearling & Apr 22 & 340 & 95 & 90 & Oct 8-Oct 8 & 2.5 & 2.6 \\
no. 6F & Yearling & Apr 24 & 338 & 95 & 89 & Nov 3-Nov 15 & 24.3 & 30.8 \\
no. 7F & Adult & May 14 & 342 & 94 & 88 & Oct 31-Nov 3 & 10.5 & 15.3 \\
no. 12M & Adult & May 20 & 209 & 81 & 86 & Sep 17-Sep 22 & 17.1 & 18.1 \\
no. 13F & Adult & May 21 & 386 & 93 & 89 & Oct 20-Oct 22 & 8.6 & 10.2 \\
\hline
\end{tabular}

${ }^{\mathrm{a}} \mathrm{M}$ and $\mathrm{F}$ refers to sex.

b 3 D fix percentage of total successful fixes. 

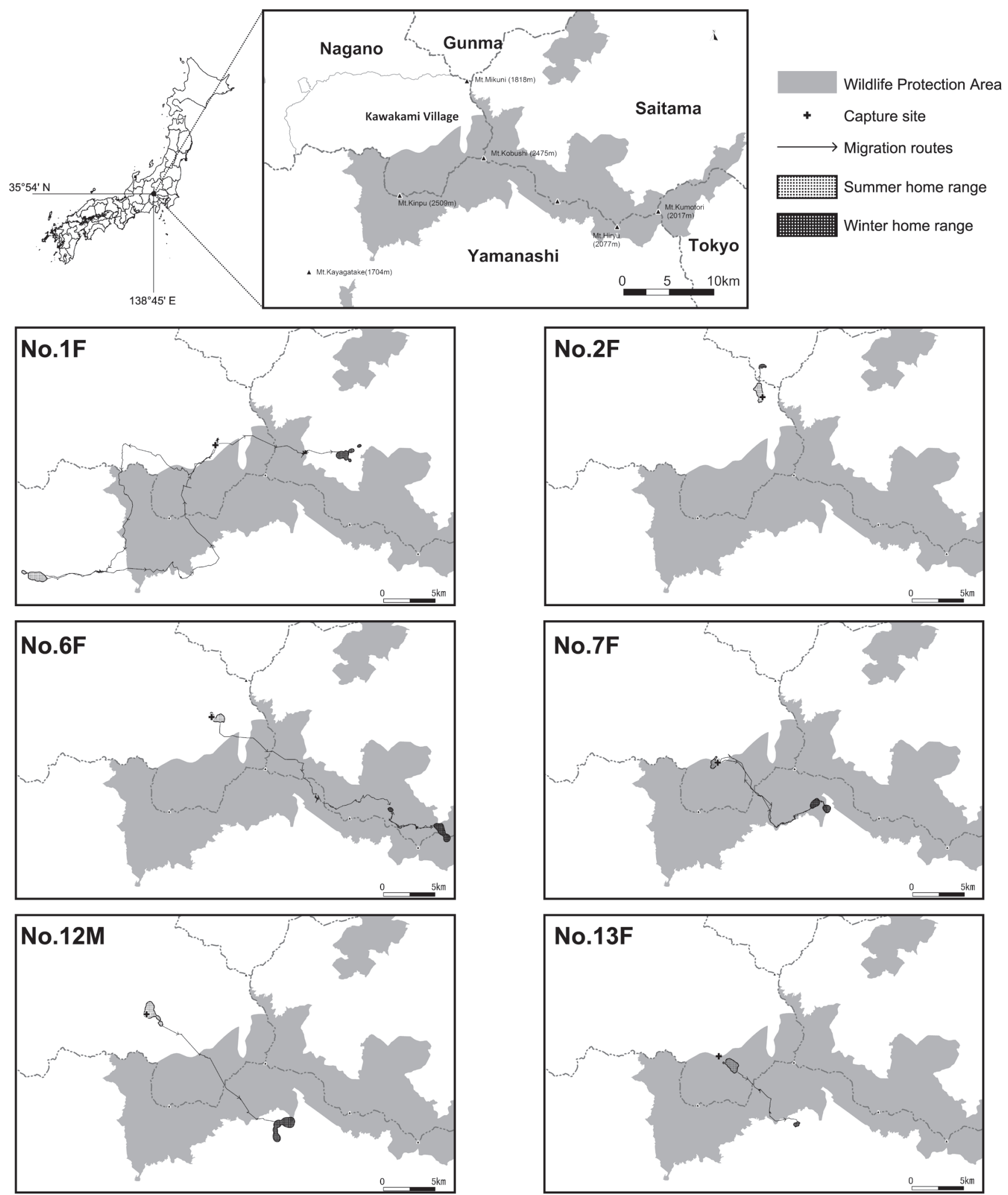

Fig. 1. Seasonal movements and home ranges of the 6 GPS collared sika deer captured at Kawakami Village, Nagano in spring 2009. The upper figure shows the study area in the Oku-Chichibu Mountains, which extends across Nagano, Yamanashi, Saitama and Gunma Prefecture. The prefectural border shown in thick grey dashed double-dotted line, which is also the ridgeline of the mountains. 

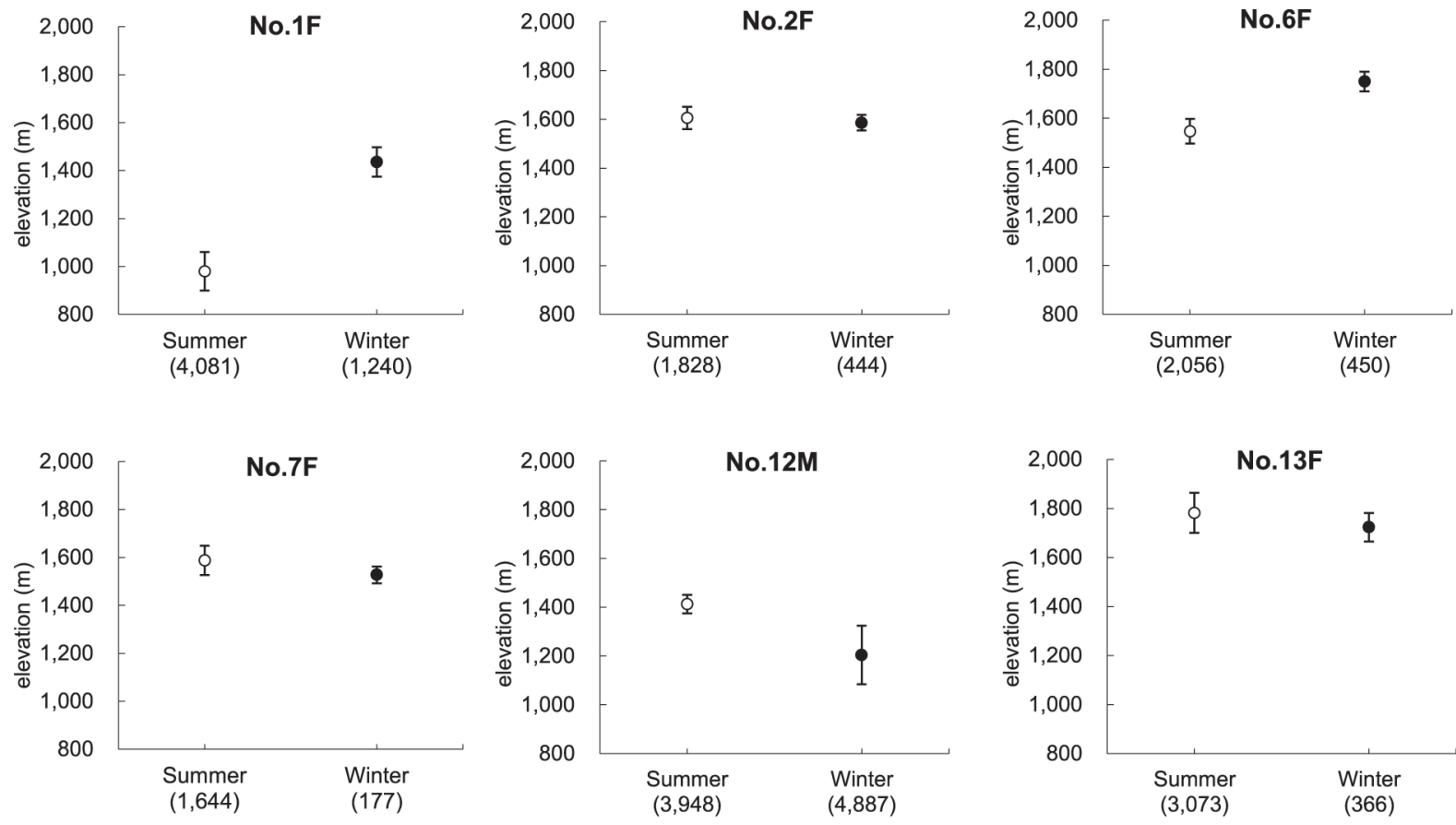

Fig. 2. Mean elevation of the summer and the winter $50 \%$ core area of the GPS collared deer captured in Kawakami Village, Nagano. Error bars indicate the standard deviation $(S D)$ and the numbers of the 10-meter DEM values are indicated below the x-axis. Elevations of each deer were significantly different between the summer and the winter (Mann-Whitney test, $P<0.001$ ).

Table 2. Summer and winter home range size of GPS collared deer captured in Kawakami Village, Nagano, with $>6$ months tracking

\begin{tabular}{clccc}
\hline \multirow{2}{*}{ Deer } & Season & $\begin{array}{c}\text { Number of } \\
\text { Locations }\end{array}$ & \multicolumn{2}{c}{ Fixed Kernel (ha) } \\
\cline { 4 - 5 } no. 1F & Summer & 8,388 & 141 & $50 \%$ \\
& Winter & 5,872 & 111 & 33 \\
no. 2F & Summer & 7,664 & 100 & 10 \\
& Winter & 7,835 & 19 & 4 \\
no. 6F & Summer & 8,628 & 82 & 17 \\
& Winter & $1,765(4,335)$ & $123(15)$ & $29(4)$ \\
no. 7F & Summer & 7,462 & 54 & 13 \\
& Winter & $2,670(3,620)$ & $30(15)$ & $6(2)$ \\
no. 12M & Summer & 4,924 & 180 & 15 \\
& Winter & 3,163 & 217 & 40 \\
no. 13F & Summer & 6,625 & 112 & 25 \\
& Winter & 6,527 & 19 & 3 \\
\hline
\end{tabular}

${ }^{a}$ Home-range size of the second winter home range is shown in parentheses.

Linear migration distance ranged from 2.5 to $31.9 \mathrm{~km}$ $(15.8 \pm 10.8 \mathrm{~km}, n=6)$, whereas actual distance ranged from 2.6 to $47.3 \mathrm{~km}(20.7 \pm 16.0 \mathrm{~km}, n=6)$. Deer no. $1 \mathrm{~F}$ showed the longest migration distance among the 6 deer, and a notable difference of $15.4 \mathrm{~km}$ between linear and actual migration was observed.

Compared to the summer, female deer reduced the $95 \%$ home range $(\mathrm{Z}=-2.023, n=5, P<0.05)$ and core area size in the winter $(\mathrm{Z}=-2.032, n=5, P<0.05)$. The home range size of male deer (no. $12 \mathrm{M}$ ) was greater than the females for both seasons (Table 2).

Although 3 deer (nos. 1F, 2F and 6F) stopped acquiring GPS fixes due to low battery while the deer was in their winter home range, we identified the deer until May 2010 by VHF telemetry. Except for 2 deer with GPS malfunction, all the deer returned to their previous summer home range. We were able to obtain both autumn and spring migration data from deer nos. $1 \mathrm{~F}$ and $7 \mathrm{~F}$.

\section{Seasonal range characteristics}

All the deer exhibited a significant difference between the mean elevations of summer and winter core areas (Fig. 2). Compared to the summer home range, 2 out of 6 deer (nos. $1 \mathrm{~F}$ and $6 \mathrm{~F}$ ) migrated to a significantly higher elevation winter home range (i.e. upward migrants) whose elevation difference was 456 and $144 \mathrm{~m}(P<$ 0.001 ). On the contrary, 4 deer (nos. $2 \mathrm{~F}, 7 \mathrm{~F}, 12 \mathrm{M}$ and $13 \mathrm{~F}$ ) wintered in a significantly lower elevation (i.e. downward migrants), the difference being 20 to $209 \mathrm{~m}$ 
Table 3. Proportions of steep slope, southerly aspects, coniferous cover, Wildlife Protection Area (WPA), bamboo grass MDR and road density in summer and winter home range of GPS collared deer. Chi-square test was used to compare the percentage of individual deer's summer and winter home range.

\begin{tabular}{|c|c|c|c|c|c|c|c|}
\hline \multirow{2}{*}{ Characteristics } & & \multicolumn{6}{|c|}{ Deer } \\
\hline & & no. $1 \mathrm{~F}$ & no. $2 \mathrm{~F}$ & no. $6 \mathrm{~F}$ & no. $7 \mathrm{~F}$ & no. $12 \mathrm{M}$ & no. $13 \mathrm{~F}$ \\
\hline \multirow[t]{2}{*}{ Slope $\geq 30^{\circ}(\%)$} & Summer & 16.4 & 27.0 & 42.8 & 35.5 & 35.6 & 59.1 \\
\hline & Winter & $79.1 * * *$ & $63.5^{* * *}$ & $72.0 * * *$ & $28.7^{\mathrm{ns}}$ & $54.3 * * *$ & $84.0^{* * *}$ \\
\hline \multirow[t]{2}{*}{ Southerly Aspects (\%) } & Summer & 10.1 & 68.8 & 10.6 & 58.0 & 17.4 & 29.3 \\
\hline & Winter & $1.8^{* * *}$ & $93.7 * * *$ & $67.8 * * *$ & $84.0 * * *$ & $56.4 * * *$ & $84.8^{* * *}$ \\
\hline \multirow[t]{2}{*}{ Coniferous Cover (\%) } & Summer & 0.0 & 0.0 & 0.0 & 0.0 & 0.0 & 38.5 \\
\hline & Winter & $11.8^{* * *}$ & $0.0^{\mathrm{ns}}$ & $55.6^{* * *}$ & $2.7^{\mathrm{ns}}$ & $23.5^{* *}$ & $81.6^{* * *}$ \\
\hline \multirow[t]{2}{*}{ WPA (\%) } & Summer & 0.0 & 0.0 & 0.0 & 97.9 & 0.0 & 100.0 \\
\hline & Winter & $0.0^{\mathrm{ns}}$ & $0.0^{\mathrm{ns}}$ & $100.0 * * *$ & $96.7^{\mathrm{ns}}$ & $9.0^{\mathrm{ns}}$ & $0.0 * * *$ \\
\hline \multirow[t]{2}{*}{ Bamboo grass MDR/frequency ${ }^{\mathrm{a}}$} & Summer & - & - & - & - & - & - \\
\hline & Winter & $1.1 / 100^{\mathrm{b}}$ & $0.7 / 100^{\mathrm{b}}$ & $0.6 / 100^{\mathrm{c}}$ & $1.3 / 100^{\mathrm{b}}$ & $0.1 / 100^{\mathrm{b}}$ & $0.6 / 100^{c}$ \\
\hline \multirow[t]{2}{*}{ Road density $(\mathrm{m} / \mathrm{ha})^{\mathrm{d}}$} & Summer & 12.7 & 13.6 & 14.6 & 19.4 & 21.5 & 3.5 \\
\hline & Winter & 0.0 & 0.0 & 0.0 & 0.0 & 5.9 & 0.0 \\
\hline
\end{tabular}

Significance levels are ${ }^{\text {ns }} P>0.05 ; * * P<0.01 ; * * * P<0.001$.

${ }^{a}$ Frequency (\%) of appearance of bamboo grass in each survey site.

${ }^{\mathrm{b}}$ Sasamorpha borealis.

'Sasa hayatae.

${ }^{\mathrm{d}}$ Road density is calculated within $95 \%$ home range.

$(P<0.001)$. The downward migrants except for the male deer (no. $12 \mathrm{M}$ ) exhibited relatively small elevation difference $(<70 \mathrm{~m})$ compared to the upward migrants.

Five out of 6 deer utilized significantly higher percentage of steep slope $\left(\geq 30^{\circ}\right)$ and southerly aspects in the winter compared to the summer $(P<0.001$; Table 3$)$. Four deer (nos. 1F, 6F, 12M and 13F) showed significantly higher percentage of coniferous cover in the winter $(P<0.001)$.

Utilization of the wildlife protection area (WPA) varied among seasons and individuals (Fig. 1 and Table 3). Only 2 deer (nos. 6F and 7F) showed intense utilization of the WPA during winter.

Bamboo grass was not identified in the summer core area for all the deer (Table 3), whereas bamboo grass (Sasamorpha borealis or Sasa hayatae) dominated in the winter core area. The bamboo grass MDR $\left(\mathrm{m}^{3} / \mathrm{m}^{2}\right)$ was only 0.1 for the male deer (no. $12 \mathrm{M}$ ) because the bamboo grass was dwarf and scattered.

The road density $(\mathrm{m} / \mathrm{ha})$ of the summer home range ranged from 3.5 to $21.5 \mathrm{~m} / \mathrm{ha}$, whereas road was not identified in the winter home range except for deer no. $12 \mathrm{M}$.

\section{Discussion}

\section{Long-distance migration}

The GPS collared deer on our study area in the OkuChichibu Mountains were all migratory and migrated $2.5-31.9 \mathrm{~km}($ mean $=15.9 \mathrm{~km})$. The linear migration distance observed in our study is the longest in the temperate region of Honshu, Japan (Maruyama 1981 $[5.1 \mathrm{~km}, n=1]$; Honma $1995[11.1 \mathrm{~km}$, range $=8.2$ $14.4 \mathrm{~km}, n=10])$. Furthermore, two female deer migrated over a distance of $20 \mathrm{~km}(24.3 \mathrm{~km}$ and $31.9 \mathrm{~km})$ showed the longest distance reported in Honshu. In eastern Hokkaido, deer are known to migrate a long distance (Uno and Kaji 2000 [19.9 km, range $=2.5-42.0$ $\mathrm{km}, n=22]$; Igota et al. $2004[35.1 \mathrm{~km}$, range $=7.2-$ $101.7 \mathrm{~km}, n=39]$ ) due to heavy snow and limited distribution of coniferous forests (Igota et al. 2004). In Honshu, sika deer were considered not to migrate such long distance, because of the fragmented deer habitat (Yabe and Takatsuki 2009). However, a recent study reported that a single male deer migrated over $20 \mathrm{~km}$ in the alpine zone of South Alps, central Japan (Izumiyama et al. 2009). South Alps, as well as Oku-Chichibu Mountains are one of the major mountainous regions of Japan, which holds extensive areas of uncultivated 
land. The fact that the GPS collared deer in our study migrated north or eastwards to the mountainous region, and furthermore utilized the highest mountain ridges as a corridor during migration may be an indication of deer avoiding human activity. The extensive areas of uncultivated land are most likely to be the reason why it was possible for deer to migrate a long-distance.

It is noteworthy that the actual migration distance of deer no. $1 \mathrm{~F}$ was $15.5 \mathrm{~km}$ longer than the linear distance, whereas the other deer exhibited relatively small difference. In order to minimize energy expenditure, deer most certainly migrate linearly. However, the migration route of this deer was circuitous between its summer home range and the north of Mt. Kinpu. Since there are deep and rocky valleys in the southern regions of Mt. Kinpu and Mt. Kobushi, the topographic feature of this area may have been a hindrance for deer no. $1 \mathrm{~F}$ to migrate linearly.

\section{Seasonal home range}

The home range sizes for the female deer decreased in the winter. Several studies also reported a difference between summer and winter home range size (Nelson and Mech 1981; Tierson et al. 1985; Nicholson et al. 1997). Home range size is influenced by animal's energy requirements, habitat productivity or population density (Hudson and White 1985; Kilpatrick et al. 2001). During winter, deer decreases metabolic activity (Silver et al. 1969) and voluntary food intake (Hudson and White 1985). These female deer wintered in high altitude areas (range $=1,436-1,723 \mathrm{~m}$ ), thus may have reduced the winter home range size as a consequent of that phenomenon.

Four female deer without GPS malfunction returned to their previous summer home range. Although we were not able to track the deer during the second season, previous studies indicate high fidelity to summer home range of deer (e.g., Tierson et al. 1985; Porter et al. 1991; Igota et al. 2004), which is consistent with our results.

Two deer (nos. 6F and 7F) had two distinctive winter home ranges. Hunting or hunting dogs may be the cause for deer to leave its range temporary (Sweeney et al. 1971; Morgantini and Hudson 1985; Vercauteren and Hygnstrom 1998; Sunde et al. 2009). Management hunting was conducted at the ridgeline of Mt. Kumotori and Mt. Hiryu, within deer no. 6F's first winter home range, using dogs for consecutive 2 days in mid December 2009, and one deer was harvested. Deer no. 6F left her first winter home range on December 25 and never came back. It is most likely that this deer shifted her home range because of hunting activities. However, the reason for deer no. 7F to shift the winter home range was speculative, since hunting was not conducted during the winter in the area.

\section{Autumn migration}

Based on the seasonal elevation use, the GPS collared deer exhibited upward and downward migration. Migratory deer rarely exhibits upward migration (Igota et al. 2004; Pépin et al. 2008), while downward migration is more common to avoid low temperatures and deep snow (e.g., Boyce 1991; Nelson 1995; Nicholson et al. 1997; D'Eon and Serrouya 2005; Ramanzin et al. 2007; Fieberg et al. 2008). In our study, all the deer wintered in relatively high elevation areas $(>1,200 \mathrm{~m}$ a.s.l.), and elevation difference of upward migrants (range $=144$ $456 \mathrm{~m}, n=2$ ) was greater, whereas elevation difference of downward migrants was considerably small (range = 20-209 m, mean $=87 \mathrm{~m}, n=4)$ compared to that observed by Igota et al. (2004) (upward: mean $=113 \mathrm{~m}$, downward: mean $=227 \mathrm{~m}$ ). This was probably relative to the less snow accumulation in the study area.

Snow limits the movement, increasing energy expenditure and reduces forage availability of deer (Parker et al. 1984). In Honshu, deer avoid deep snow (>50 cm) (Maruyama 1981; Takatsuki 1992), and its activity or forage availability was determined by the duration of heavy snow (Maruyama 1981). Although we did not measure the actual snow depth in the study area, according to Japan Meteorological Agency (2002), the maximum snow depth in the summer and winter home ranges were 17 to $43 \mathrm{~cm}$ and 28 to $37 \mathrm{~cm}$, respectively. At Nobeyama meteorological weather station, adjacent to Kawakami Village, from December 2009 to March 2010 the maximum precipitation and the number of days (shown in parenthesis) with total precipitation of more than $1.0 \mathrm{~mm}$ recorded was $18.5 \mathrm{~cm}$ (5 days), $12.5 \mathrm{~cm}$ (5 days), $16.0 \mathrm{~cm}$ (10 days), $37.0 \mathrm{~cm}$ (17 days), respectively (Meteorological data of Nagano Prefecture, Nagano Local Meteorological Observatory, Nagano). These data suggest that snow was less likely to hinder the locomotion of the deer. The small downhill movements of the downward migrants (i.e. even the deer with highest summer home range exhibited only $77 \mathrm{~m}$ elevation difference), are also indicative of less snow cover in the study area.

Meanwhile, not only elevation but also snow cover patterns determine the suitability of the winter habitat of 


\section{(A)}

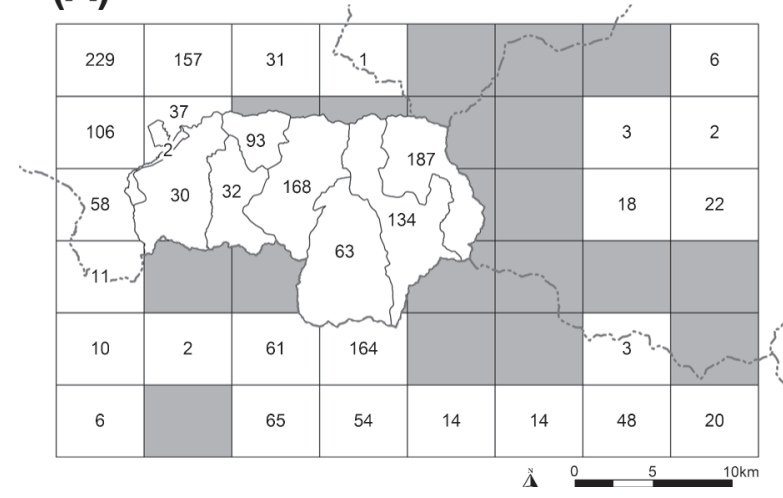

(B)

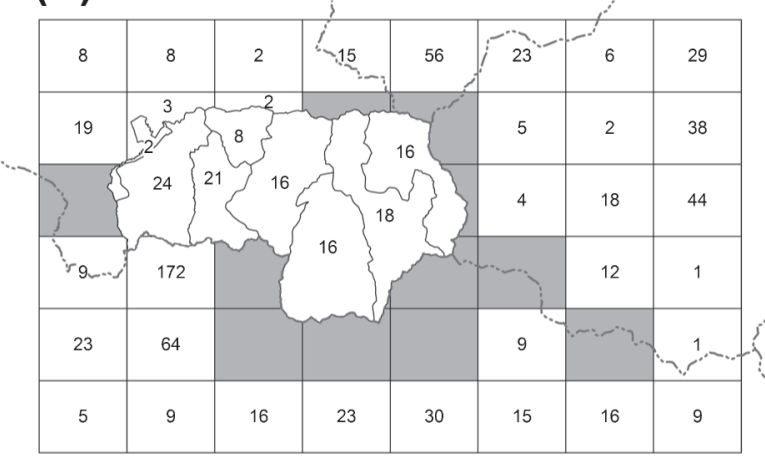

Fig. 3. Number of deer harvested during non-hunting season (A) and hunting season (B) in the study area shown in 5-km grid, 2009. Grey shadow polygons indicate deer were not harvested during the season. Number of deer harvested in Kawakami Village are shown in local district because of the insufficient information on the grid data. Number of deer harvested with unknown capture site in Kawakami Village during nonhunting season and hunting season was 17 and 1, respectively. The prefectural border is shown in thick grey dashed double-dotted line.

deer (Schmidt 1993). Igota et al. (2004) found that the upward migrants wintered in less snow areas and utilized more coniferous cover in the winter, because of relatively small snow depth under canopy closure (D'Eon 2004). Pépin et al. (2008) suggested that the male red deer (C. elaphus L.) migrated to higher elevation winter range with less snow by utilizing steeper slopes. Further, snow accumulation is usually smaller in southerly aspects. It is most certainly that the two upward migrants in our study did not necessarily winter in areas of less snow. Deer no. 1F probably wintered in areas of more snow because of considerable uphill movement (456 m), but given the low percentage of southerly aspects and coniferous cover, snowfall may not be a menace to this deer. On the contrary, deer no. $6 \mathrm{~F}$, which wintered in higher elevation (1,722 $\mathrm{m}$ a.s.1.) utilized high percentage of steep slope, southerly aspects and coniferous cover, which is in agreement with Igota et al. (2004) and Pépin et al. (2008), utilizing less snow.

Most authors of previous studies on migratory sika deer concluded that autumn migration was caused by snow (Maruyama 1981; Takatsuki et al. 2000; Igota et al. 2004). However, given the less snow accumulation and the altitudinal migration patterns, it is likely that snow is not the sole cause of autumn migration in our study area.

Lack of bamboo grass in the summer home range also suggests that winter forage may be one of the factors influencing the autumn migration. Bamboo grass is the most important winter forage of sika deer in central to northern Honshu (Furubayashi and Maruyama 1977; Takatsuki 2009), which contains the highest crude protein contents and availability (Yamane 1999). Igota et al.
(2004) revealed that bamboo grass variety contributed to the migration patterns of sika deer. Furthermore, population density of sika deer during winter was significantly higher in areas with high bamboo grass availability (Yamane 1999). Thus, we suggest that the bamboo grass affected the autumn migration of the GPS collared deer.

The number of deer harvested during hunting season in the winter home range of the deer was small (range $=$ 0-4) compared to the summer home range, except for deer no. 2F (Fig. 3). Although this deer wintered in a section where 56 deer were harvested during the hunting season, hunting was not conducted within or in the adjacent areas of the winter home range (Nakayama Hiroyuki, a hunter, Gunma Prefectural Office, personal communication). Therefore, we conclude that all the GPS collared deer wintered in the areas with low hunting pressure.

On the contrary, the number of deer harvested during non-hunting season was considerably high in Kawakami Village in 2009 (Fig. 3), which was almost 6 and 3 times the number of deer harvested in 2007 and 2008, respectively. Presumably, the unusual hunting pressure of 2009 and the high fidelity to summer home range (e.g., Igota et al. 2004) explain why the deer stayed in the intensive hunting areas during the summer.

Departure from the summer home range occurred more than 12 days prior to the hunting season for all the deer, and some deer started to stay in their winter home range from late September and early October. Given that all the deer wintered in areas with less hunting pressure, one reason for the deer to migrate prior to the hunting season may be to avoid hunting. 
The road density within the winter home range was smaller than the summer for all the deer. There were multiple agricultural and timber roads with relatively heavy traffic in the summer home range. Conversely, in the winter home range, there were no agricultural roads and the closest timber roads were closed to traffic during winter, and winter activities (i.e. skiing or hiking) are not very common in Oku-Chichibu Mountains due to its rocky and steep topography. Thus, the deer wintered in places with less human activities more likely to avoid human disturbance.

Furthermore, the fact that the deer utilized steeper slopes and high elevations may also relate to its tendency to avoid human activities, which clearly decreases with steeper slopes and higher elevations. In general, deer avoid using steep slopes (Ganskopp and Vavra 1987) and it is best to remain undisturbed in order to minimize unnecessary energy loss in winter (Moen 1976). Schmidt (1993) described that Austrian Alps red deer winter habitat was based on energy conservation and on minimizing energy expenditures, which corresponds to our results.

The WPA, a protected area may function as a refuge during hunting season (Kanagawa Prefecture 2007; Grignolio et al. 2011). Although we expected most deer to utilize the WPA, only two deer (nos. 6F and 7F) mainly utilized the WPA during winter. It is speculative if the deer utilized the WPA as a refuge due to a small number of deer analyzed. However, our results indicate that there are safe areas outside the WPA, because the GPS collared deer most certainly wintered in areas with little human disturbances.

The autumn migration of the GPS collared deer was affected by both winter forage and human activities in the western foothills of the Oku-Chichibu Mountains. Our results may show the situation where deer migrated from the summer home range to access abundant winter forage and to reduce human disturbance, likely hunting pressures, at the risk of considerable energy expenditures through long-distance migration and crossing the main ridge of the mountains.

Acknowledgments: We would like to thank the Kawakami Village Office for supporting this study. Yamanashi, Saitama and Gunma Prefectural Office provided the information on the wildlife protection area and deer harvest data. We are grateful to H. Nakayama for the comments on hunting activities. Two anonymous reviewers provided useful comments, which helped us to improve the manuscript. We also thank S. Shimosaka, K. Kido, K. Tahara and A. Kawai for their assistance in the fieldwork.

\section{References}

Boyce, M. S. 1991. Migratory behavior and management of elk (Cervus elaphus). Applied Animal Behaviour Science 29: 239350.

Calenge, C. 2006. The package "adehabitat" for the R software: A tool for the analysis of space and habitat use by animals. Ecological Modelling 197: 516-519.

Craighead, J. J., Atwell, G. and O'Gara, B. W. 1972. Elk migrations in and near Yellowstone National Park. Wildlife Monographs 29: 3-48.

D'Eon, R. G. 2004. Snow depth as a function of canopy cover and other site attributes in a forested ungulate winter range in southeast British Columbia. BC Journal of Ecosystems and Management 3: 1-9.

D'Eon, R. G. and Serrouya, R. 2005. Mule deer seasonal movements and multiscale resource selection using global positioning system radiotelemetry. Journal of Mammalogy 86: 736-744.

D’Eon, R. G., Serrouya, R., Smith, G. and Kochanny, C. O. 2002. GPS radiotelemetry error and bias in mountainous terrain. Wildlife Society Bulletin 30: 430-439.

ESRI. 1996. ArcView Spatial Analyst, ESRI. Redlands, CA.

Fieberg, J., Kuehn, D. W. and DelGiudice, G. D. 2008. Understanding variation in autumn migration of northern white-tailed deer by long-term study. Journal of Mammalogy 89: 1529-1539.

Fryxell, J. M. and Sinclair, A. R. E. 1988. Causes and consequences of migration by large herbivores. Trends in Ecology and Evolution 3: 237-241.

Furubayashi, K. and Maruyama, N. 1977. Food habits of sika in Fudakake, Tanzawa Mountains. Honyurui Kagaku [Mammalian Science] 7: 55-62 (in Japanese with English abstract).

Ganskopp, D. and Vavra, M. 1987. Slope use by cattle, feral horses, deer, and bighorn sheep. Northwest Science 61: 74-81.

Garrott, R. A., White, G. C., Bartmann, R. M., Carpenter, L. H. and Alldredge, A.W. 1987. Movements of female mule deer in northwest Colorado. Journal of Wildlife Management 51: 634-643.

Grignolio, S., Merli, E., Bongi, P., Ciuti, S. and Apollonio, M. 2011. Effects of hunting with hounds on a non-target species living on the edge of a protected area. Biological Conservation 144: 641649.

Hayne, D. W. 1949. Calculation of size of home range. Journal of Mammalogy 30: 1-18.

Honma, K. 1995. Movement Patterns and Habitat Use of Sika Deer (Cervus nippon) in Oku-Nikko and Ashio Area. Master's Thesis, Graduate School of Education, Joetsu University of Education, 60 pp. (in Japanese).

Hudson, R. J. and White, R. G. 1985. Bioenergetics of Wild Herbivores. CRC Press, Inc. Boca Raton, 314 pp.

Igota, H., Sakuragi, M., Uno, H., Kaji, K., Kaneko, M., Akamatsu, R. and Maekawa, K. 2004. Seasonal migration patterns of female sika deer in eastern Hokkaido. Ecological Research 19: 169-178.

Izumiyama, S. and Mochizuki, T. 2008. Seasonal range use of sika deer which inhabits the sub-alpine zone in the Southern Japan Alps. Bulletin of Shinshu University AFC 6: 25-32 (in Japanese with English summary).

Izumiyama, S., Mochizuki, T. and Takii, A. 2009. GPS tracking of sika deer which inhabits the sub-alpine zone in the Southern Japan Alps. Bulletin of Shinshu University AFC 7: 63-71 (in Japanese with English summary).

Japan Meteorological Agency. 2002. Mesh Climatic Data 2000, 
Tokyo (in CD-ROM).

Kamei, T., Takeda, K., Izumiyama, S. and Oshima, K. 2010. The effect of hunting on the behavior and habitat utilization of sika deer (Cervus nippon). Mammal Study 35: 235-241.

Kanagawa Prefecture. 2007. The Second Plan for Conservation and Management of Sika Deer in Kanagawa Prefecture. Kanagawa Prefecture Department of Environment and Agriculture, 44 pp. (in Japanese).

Kilpatrick, H. J., Spohr, S. M. and Lima, K. K. 2001. Effects of population reduction on home ranges of female white-tailed deer at high densities. Canadian Journal of Zoology 79: 949-954.

Kobayashi, H., Nakamura, Y. and Watanabe, Y. 2003. Analysis of weed vegetation of no-tillage upland field based on the multiplied dominance ratio. Weed Biology and Management 3: 77-92.

Kufeld, R. C., Bowden, D. C. and Schrupp, D. L. 1988. Influence of hunting on movements of female mule deer. Journal of Range Management 41: 70-72.

Kufeld, R. C., Bowden, D. C. and Schrupp, D. L. 1989. Distribution and movements of female mule deer in the Rocky Mountain foothills. Journal of Wildlife Management 53: 871-877.

Maruyama, N. 1981. A study of the seasonal movements and aggregation patterns of sika deer. Bulletin of Faculty of Agriculture, Tokyo University of Agriculture and Technology 23: 1-85 (in Japanese with English summary).

Ministry of the Environment. 1979a. Report on the Second National Survey on a Natural Environment of Vegetation (Saitama Prefecture). Nature Conservation Bureau, Tokyo, 296 pp. (in Japanese).

Ministry of the Environment. 1979b. Report on the Second National Survey on a Natural Environment of Vegetation (Gunma Prefecture). Nature Conservation Bureau, Tokyo, 56 pp. (in Japanese).

Ministry of the Environment. 1988. Report on the Third National Survey on a Natural Environment of Vegetation (Yamanashi Prefecture). Nature Conservation Bureau, Tokyo, 159 pp. (in Japanese).

Ministry of the Environment. 1997. Japan Integrated Biodiversity Information System (J-IBIS). http://www.biodic.go.jp/index_ e.html.

Moen, A. N. 1976. Energy conservation by white-tailed deer in the winter. Ecology 57: 192-198.

Morgantini, L. E. and Hudson, R. J. 1985. Changes in diets of wapiti during a hunting season. Journal of Range Management 38: 77 79.

Nagano Prefecture. 1976. Vegetation of Nagano Prefecture. Nagano Prefecture Department of Life Environment, 137 pp. (in Japanese).

Nagano Prefecture. 2011. The Third Plan for Conservation and Management of Sika Deer in Nagano Prefecture. Nagano Prefecture Department of Forestry, 48 pp. (in Japanese).

Nagata, K. 2005. Home range characteristic of sika deer in Fudakake of Tanzawa Mountains. Honyurui Kagaku [Mammalian Science] 45: 25-33 (in Japanese with English abstract).

Nakata, M. 1987. Studies on the forest vegetation and soils, and its vertical zonality in the subalpine zone of Okuchichibu Mountains (Preliminary report). Bulletin of Tokyo University Department of Forestry 76: 87-105 (in Japanese).

Nelson, M. E. 1995. Winter range arrival and departure of whitetailed deer in northeastern Minnesota. Canadian Journal of Zoology 73: 1069-1076.

Nelson, M. E. and Mech, L. D. 1981. Deer social organization and wolf predation in northeastern Minnesota. Wildlife Monographs 77: 5-53.

Nicholson, M. C., Bowyer, R. T. and Kei, J. G. 1997. Habitat selection and survival of mule deer: tradeoffs associated with migration. Journal of Mammalogy 78: 483-504.

Parker, K. L., Robbins, C. T. and Hanley, T. A. 1984. Energy expenditures for locomotion by mule deer and elk. Journal of Wildlife Management 48: 474-488.
Pellerin, M., Saïd, S. and Gaillard, J-M. 2008. Roe deer Capreolus capreolus home-range sizes estimated from VHF and GPS data. Wildlife Biology 14: 101-110.

Pépin, D., Adrados, C., Janeau, G., Joachim, J. and Mann, C. 2008 Individual variation in migratory and exploratory movements and habitat use by adult red deer (Cervus elaphus L.) in a mountainous temperate forest. Ecological Research 23: 1005-1013.

Porter, W. F., Mathews, N. E., Underwood, H. B., Sage, Jr. R. W. and Behrend, D. F. 1991. Social organization in deer: Implications for localized management. Environmental Management 15: 809814.

Ramanzin, M., Sturaro, E. and Zanon, D. 2007. Seasonal migration and home range of roe deer (Capreolus capreolus) in the Italian eastern Alps. Canadian Journal of Zoology 85: 280-289.

Sakuragi, M., Igota, H., Uno, H., Kaji, K., Kaneko, M., Akamatsu, R. and Maekawa, K. 2003. Seasonal habitat selection of and expanding sika deer Cervus nippon population in eastern Hokkaido, Japan. Wildlife Biology 9: 141-153.

Schmidt, K. 1993. Winter ecology of nonmigratory Alpine red deer. Oecologia 95: 226-233.

Shigematsu, Y., Asada, M. and Ochiai, K. 1995. Radio-tracking of individuals. Chiba Prefecture and Boso Deer Research Group, Research report on sika deer management in Boso Penninsula 3: 54-72 (in Japanese)

Silver, H., Colovos, N. F., Holter, J. B. and Hayes, H. H. 1969. Fasting metabolism of white-tailed deer. Journal of Wildlife Management 33: 490-498.

Sunde, P., Olesen, C. R., Madsen, T. L. and Haugaard, L. 2009. Behavioural responses of GPS-collared female red deer Cervus elaphus driven to hunts. Wildlife Biology 15: 454-460.

Sweeney, J. R., Marchinton, R. L. and Sweeney, J. M. 1971. Responses of radio-monitored white-tailed deer chased by hunting dogs. Journal of Wildlife Management 35: 707-716.

Takatsuki, S. 1992. Foot morphology and distribution of sika deer in relationship to snow depth in Japan. Ecological Research 7: 1923.

Takatsuki, S. 2009. North-south variations in sika deer ecology as a forest-dwelling cervid. In (D. R. McCullough, S. Takatsuki and K. Kaji, eds.) Sika Deer, pp. 217-230. Springer, Tokyo.

Takatsuki, S., Suzuki, K. and Higashi, H. 2000. Seasonal elevational movements of sika deer on Mt. Goyo, northern Japan. Mammal Study 25: 107-114.

Tierson, W. C., Mattfeld, G. F., Sage, R. W. and Behrend, D. F. 1985. Seasonal movements and home ranges of white-tailed deer in the Adirondacks. Journal of Wildlife Management 49: 760-769.

Uno, H. and Kaji, K. 2000. Seasonal movements of female sika deer in eastern Hokkaio, Japan. Mammal Study 25: 49-57.

Vercauteren, K. C. and Hygnstrom, S. E. 1998. Effects of agricultural activities and hunting on home ranges of female white-tailed deer. Journal of Wildlife Management 62: 280-285.

Worton, B. J. 1989. Kernel methods for estimating the utilization distribution in home-range studies. Ecology 70: 164-168.

Yabe, T. and Takatsuki, S. 2009. Migratory and sedentary behavior patterns of sika deer in Honshu and Kyushu, Japan. In (D. R. McCullough, S. Takatsuki and K. Kaji, eds.) Sika Deer, pp. 273 283. Springer, Tokyo.

Yamane, M. 1999. A study on nutritional ecology of sika deer in the eastern Tanzawa Mountains, Japan. Bulletin of Kanagawa Prefectural Forestry Research Center 25: 33-73 (in Japanese with English summary).

Zweifel-Schielly, B., Kreuzer, M., Ewald, K. C. and Suter, W. 2009. Habitat selection by an Alpine ungulate: the significance of forage characteristics varies with scale and season. Ecography 23: $103-113$

Received 17 August 2011. Accepted 21 February 2012. 